\title{
Hybrid Organic/Inorganic Coatings Through Dual-Cure Processes: State of the Art and Perspectives
}

\author{
Giulio Malucelli \\ Italy; giulio.malucelli@polito.it; Tel.: +39-0131-229369; Fax: +39-0131-229399 \\ Academic Editor: Naba Dutta \\ Received: 29 December 2015; Accepted: 26 February 2016; Published: 2 March 2016
}

Department of Applied Science and Technology, Politecnico di Torino, Viale Teresa Michel 5, 15121 Alessandria,

\begin{abstract}
This paper reviews the current state of the art related to the synthesis and characterization of hybrid organic-inorganic $(\mathrm{O} / \mathrm{I})$ coatings obtained through the exploitation of dual-cure processes, which involve a photo-induced polymerization followed by a thermal treatment: this latter allows the occurrence of sol-gel reactions of suitable alkoxy precursors already embedded in the UV-curable system. After a brief introduction on hybrid organic-inorganic coatings, the first part of the review is focused on the design and feasibility issues provided by the dual-cure method, emphasizing the possibility of tuning the structure of the final hybrid network on the basis of the composition of the starting liquid mixture. Then, some recent examples of hybrid organic-inorganic networks are thoroughly described, showing their potential advances and the application fields to which they can be addressed.
\end{abstract}

Keywords: dual-cure processes; hybrid organic-inorganic coatings; photo-induced polymerization; sol-gel reactions; functional networks; alkoxy precursors; coupling agents; thermal stability; barrier properties

\section{Introduction}

Hybrid organic-inorganic $(\mathrm{O} / \mathrm{I})$ materials or ceramers represent an interesting and up-to-date class of materials having a nanophasic morphology, where an organic phase is strictly interconnected with an inorganic one. As a consequence, the properties of these hybrids are not only the sum of the individual contributions of both organic and inorganic phases, as the role exerted by their inner interfaces may become important and predominant. Therefore, the overall properties and the behavior of the hybrid materials are strictly related to morphology of the interfaces and nanophases. More specifically, the type and morphology of the interfaces can be used in order to roughly divide these materials into two well-defined classes, namely Class I and II: in the former, organic and inorganic components are mixed together and the cohesion to the whole nanocomposite material is provided by van der Waals, hydrogen, or ionic bonds only; conversely, class II materials exhibit the two phases fairly linked together by means of strong covalent or iono-covalent bonds [1,2]. A general scheme of the morphological structure of the two aforementioned classes is shown in Figure 1.

Several pioneering studies are reported in the scientific literature, highlighting the peculiarities of these nanocomposite systems [3-6]. Indeed, these hybrids are able to combine the appealing features of ceramics (e.g., thermal stability, high elasticity modulus, and low coefficient of thermal expansion), with the high ductility and low temperature processing conditions of polymers. As clearly reported by Mascia [7] and Sanchez [8,9], ceramers are very attractive for different fields, including optical, mechanical, biomedical, and electronic applications. 


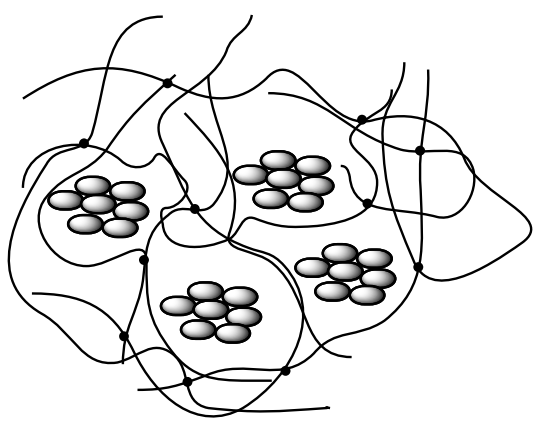

Class I

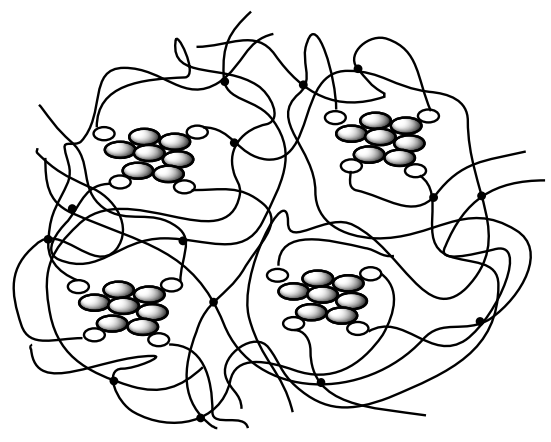

Class II

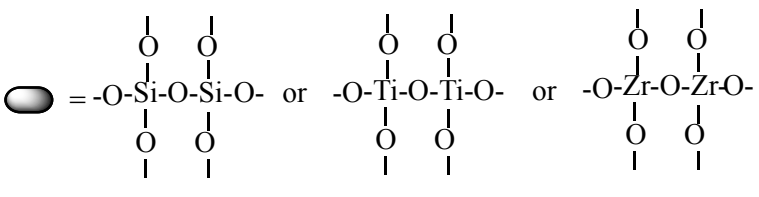

$\longrightarrow$ Polymer network

$\bigcirc=$ Coupling agent

Figure 1. Scheme of the morphological structures of Class I and II hybrid materials.

One of the major advantages related to the synthesis and processing of hybrid organic-inorganic materials is the possibility of exploiting soft chemistry routes [10] like:

- the polymerization of functional (semi)metal alkoxides, organosilanes, and macromonomers;

- the encapsulation of organic components in sol-gel derived organo-silicas or hybrid metal oxides; and

- the use of such different strategies as templated or self-assembly, nano-building block approaches, microporous metal organic frameworks, integrative synthesis, or coupled processes and so on.

Up to now, the role of different hybrid organic-inorganic systems based on silica, titania, $\mathrm{CaCO}_{3}, \mathrm{ZnO}$, has been thoroughly studied in the presence of several polymeric matrices [11-15]. From an overall point of view, the preferred way for their synthesis is the sol-gel process, which involves a two step hydrolysis and condensation reaction starting from (semi)metal alkoxides, as schematized in Figure 2 for tetraethoxysilane.

As a result, organic-inorganic networks that give rise to the formation of dispersed nanostructured phases strictly interconnected are obtained.

The overall polymerization taking place in a hybrid material represents a quite complex process, since several synthesis parameters may affect the obtained final structure. As an example, the extent of the polymerization of the inorganic network is quite crucial: indeed, the organic polymerization is always a process in competition with the formation of the inorganic network [16]. This finding can explain the reason for which the building up of the inorganic domains is usually postponed to the formation of the organic network. 
STEP 1: Hydrolysis<smiles>[R7]O[Si]([R7])([R]O[Si]([R20])([R20])O[R])[CH+]O</smiles>

STEP 2a: Condensation with formation of water

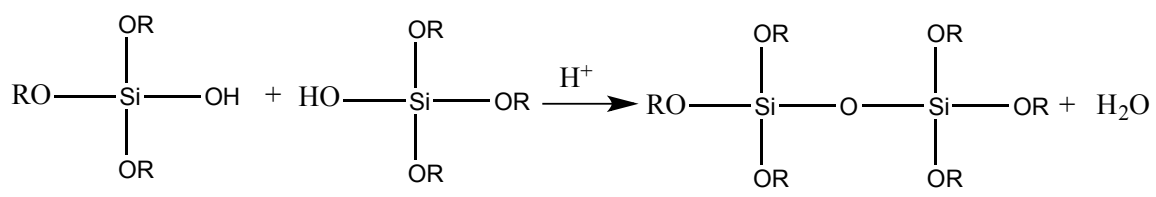

STEP 2b: Condensation with formation of alcohol

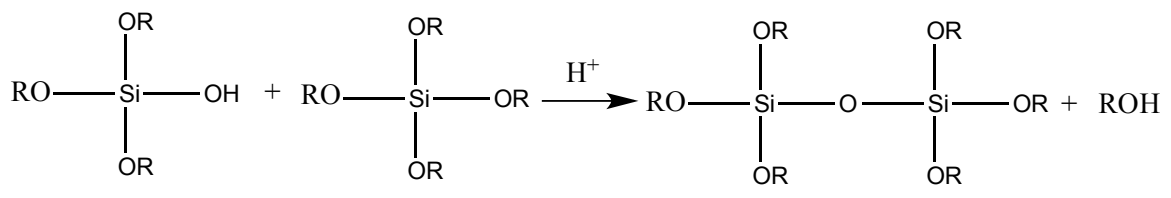

Figure 2. Hydrolysis and condensation reactions in sol-gel processes (acidic conditions).

Quite recently, several research groups started to investigate hybrid organic-inorganic materials obtained by combining a UV-initiated curing process with sol-gel reactions. The former provides high cure speed, reduced energy consumption, and absence of volatile organic compound (VOC) emissions with respect to the traditional thermally-induced polymerization processes [17].

These dual-cure processes can be successfully utilized for achieving the formation of hybrid organic-inorganic materials: in this case, a photo-initiated polymerization is followed by a thermal treatment for promoting sol-gel reactions of suitable alkoxy precursors already embedded in the UV-curable system. In doing so, it is possible to exploit the advantages connected to this fast and solvent-free radiation-induced polymerization, with the sol-gel benefits, leading to the formation of structures (usually in form of thin coatings) that show interesting peculiarities, like enhanced scratch endurance, improved abrasion, heat and radiation resistance, and suitable mechanical and optical features [18-20].

The photo-initiated polymerization process can usually be applied to all the organic-inorganic hybrids containing reactive organic functionalities, like vinyl-ether, epoxy, or acrylate groups [21]. Though, in theory, the building up of an organic network covalently bonded to the inorganic part of the hybrid material could be quite easily done by using almost all the aforementioned reactive functional groups, the first research works on UV-curable organic-inorganic hybrids have been focused on materials derived from 3-methacryloxypropyltrimethoxysilane, mainly because of its reactivity, easy processing, and high optical transparency provided to the final coating [22,23]. The reactive functional groups present in the structure of this alkoxide allow the formation of polyacrylate organic chains covalently bonded and interpenetrated with the silica backbone.

The present work aims at reviewing the current state of the art related to the synthesis and characterization of hybrid organic-inorganic $(\mathrm{O} / \mathrm{I})$ coatings obtained through dual-cure processes, emphasizing the possibility of tuning the final hybrid structure on the basis of the composition of the starting liquid system. Then, some recent examples of hybrid organic-inorganic networks are thoroughly described, showing their potentialities and the application fields to which they can be addressed. 


\section{Design of Dual-Cured Hybrid O/I Systems}

The main components and processing of dual-cure hybrid organic-inorganic coatings are schematized in Figure 3: the possible use of a coupling agent, bearing suitable functionalities for undergoing the UV-curing step, allows discriminating in between Class I and Class II hybrid materials, hence affecting the final structure and morphology of the obtained hybrid material.

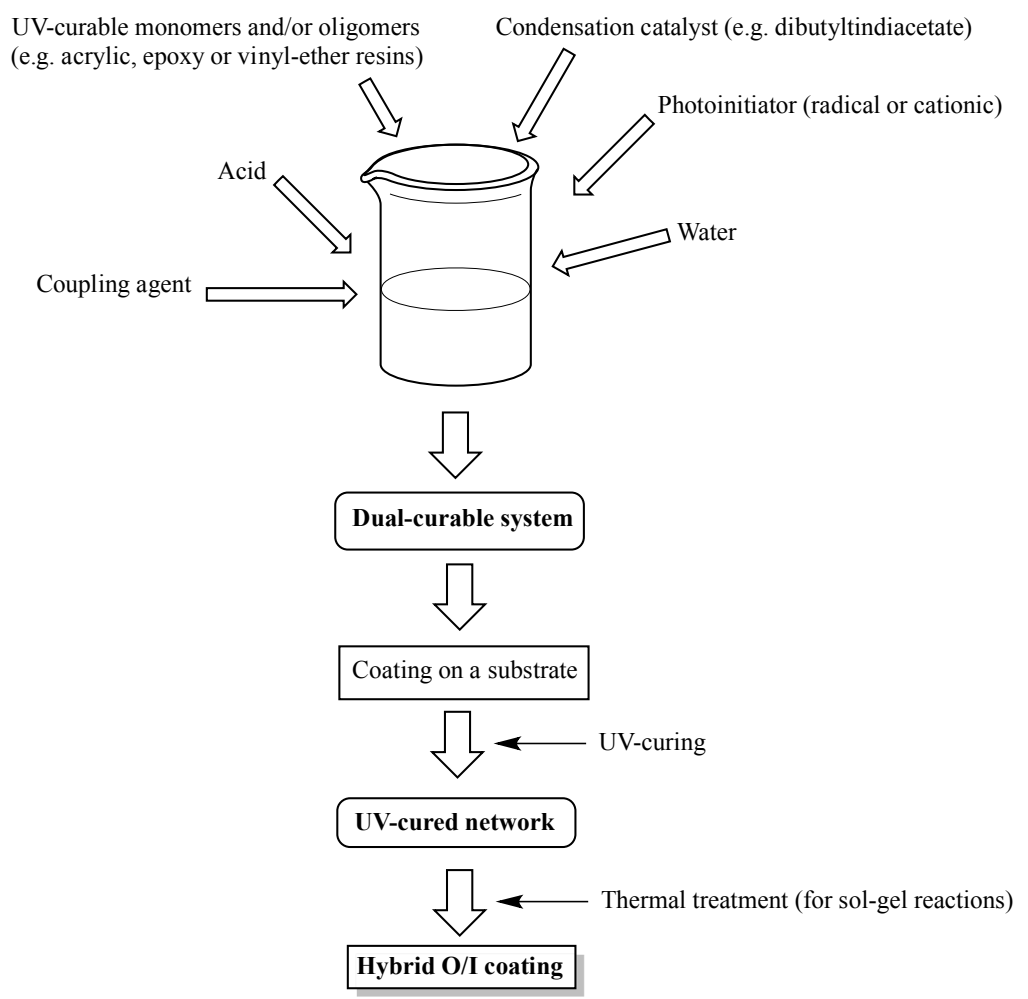

Figure 3. General hybrid O/I recipe and dual-cure processes.

There are several conditions that should be fulfilled in order to perform the dual-cure process in the best way and to obtain hybrid O/I coatings suitable for the envisaged applications. First of all, the selected sol-gel precursors have to be soluble in the UV-curable media: this condition is quite easy to satisfy, as most of the sol-gel precursors are polar enough to be dissolved in the UV-curable resins (i.e., monomers and/or oligomers). In addition, the possible presence of the coupling agent further acts as a "compatibilizer" in between the organic and inorganic liquid components.

Furthermore, the sol-gel precursors have to be reactive enough to undergo the gel formation. Usually, the presence of the inorganic phase precursors in the UV-curable "hybrid" system does not influence the photopolymerization reaction in a remarkable way $[19,24]$ : indeed, apart from a dilution effect exerted by the sol-gel precursors (which delays the gel point to higher conversion), these latter usually keep the viscosity of the system quite low, hence favoring the mobility of the propagating species involved in the UV-curing reaction.

The overall properties of the obtained hybrid material turn out to strongly depend on several experimental parameters that can be listed as follows:

- Structure of the monomers/oligomers employed in the formulation of the UV-curable systems: indeed, the flexibility and mechanical properties of the final obtained hybrid coating will be affected by the crosslinking density of the polymer network, regardless of the presence of the inorganic domains formed after the sol-gel reactions, which could further limit the mobility of the polymer segments. 
- Coupling agent: allows covalently linking the organic and inorganic phases, hence favoring the creation of strong interfaces in between the organic and inorganic parts.

- Concentration and type of (semi)metal alkoxides: they affect the rates of the both hydrolysis and condensation reactions, hence giving rise to the formation of reactive species at different rates.

- $\quad \mathrm{pH}$ : the microstructure of the oxidic phases obtained by sol-gel process depends on the hydrolysis and condensation reactions that are generally controlled by the solution $\mathrm{pH}$. More specifically, under acid-catalyzed conditions, the hydrolysis kinetics is favored instead of the condensation, which usually starts when hydrolysis is completed. Conversely, in alkali-catalyzed reactions, condensation is faster than hydrolysis, resulting in the formation of highly condensed species that may agglomerate into fine particles [25].

- Water/precursor molar ratio: the water amount in the UV-cured system that has to undergo the sol-gel process significantly influences the hydrolysis and condensation kinetics of this latter. In particular, at fixed inorganic precursor concentration, an increase in water content leads to a corresponding increase in hydrolysis and condensation rate.

- Presence of sol-gel catalysts: this allows speeding up the sol-gel reactions, hence promoting the formation of hybrid $\mathrm{O} / \mathrm{I}$ coatings with stable properties and, thus, suitable for practical uses.

Among the different properties of the final hybrid coatings, their mechanical behavior seems to be of great importance for possible industrial applications. More specifically, the mechanical properties of these materials are strictly related to their micro- and nanostructures and to the nature and extent of the organic-inorganic interfaces [26]. As a consequence, predictable mechanical properties for hybrids still represent a major challenge for hybrid materials science. Referring to hybrid coatings specifically obtained by dual-cure processes, their mechanical behavior is usually assessed by performing dynamic-mechanical tests: some results will be reported in the next paragraph.

\section{Recent Examples of Dual-Cured Hybrid O/I Systems}

This section will summarize some recent examples of hybrid organic-inorganic coatings that have been designed and prepared by using the dual-cure method described in the previous part of the manuscript. Table 1 lists the dual-cure systems that will be described, highlighting their most important features/improvements and some possible fields of application.

Table 1. Examples of dual-cured systems.

\begin{tabular}{|c|c|c|c|c|}
\hline Formulation of the Organic Part & Inorganic Precursors & Highlights & Applications & Ref. \\
\hline $\begin{array}{c}\text { Hexanediol diacrylate; Aliphatic } \\
\text { polyester urethane diacrylate; } \\
\text { Trifunctional polyester acrylate; } \\
\text { Fluoroacrylate }\end{array}$ & Methacryloxymethyltriethoxysilane & $\begin{array}{l}\text {-increased flame retardancy; } \\
\text {-hydrophobicity; } \\
\text {-good optical properties }\end{array}$ & $\begin{array}{l}\text { Transparent protective } \\
\text { coatings for flammable } \\
\text { thermoplastic substrates }\end{array}$ & [26] \\
\hline Methacrylic acid & $\begin{array}{c}\text { 3-glycidyloxypropyltrimethoxysilane; } \\
\text { Zirconium (IV) n-propoxide; } \\
\text { Tetraethoxysilane; } \\
\text { Dimethyldiethoxysilane }\end{array}$ & $\begin{array}{l}\text {-enhanced mechanical } \\
\text { properties; } \\
\text {-high thermal stability }\end{array}$ & $\begin{array}{l}\text { Dental } \\
\text { restoration/adhesion }\end{array}$ & [27] \\
\hline Diglycidyl ether of bisphenol A & n-alkyltrimethoxysilane precursors & $\begin{array}{l}\text {-enhanced corrosion } \\
\text { protection }\end{array}$ & Protective coatings & [28] \\
\hline $\begin{array}{l}\text { Perfluoropolyether } \\
\text { ethoxysilane-terminated }\end{array}$ & $\begin{array}{l}\text { 3-(trimethoxysilyl)propyl } \\
\text { methacrylate }\end{array}$ & $\begin{array}{l}\text {-hydrorepellency and } \\
\text { oleorepellency }\end{array}$ & $\begin{array}{l}\text { Hydro and oil repellent } \\
\text { finishing treatment for } \\
\text { fabrics (cotton and } \\
\text { polyester) }\end{array}$ & [29] \\
\hline $\begin{array}{l}\text { Hexafunctional aliphatic } \\
\text { polyester-acrylate }\end{array}$ & $\begin{array}{c}\text { Tetraethoxysilane; } \\
\text { 3-acryloxypropyl-trimethoxysilane }\end{array}$ & -improved scratch resistance & Protective coatings & [31] \\
\hline
\end{tabular}


Table 1. Cont

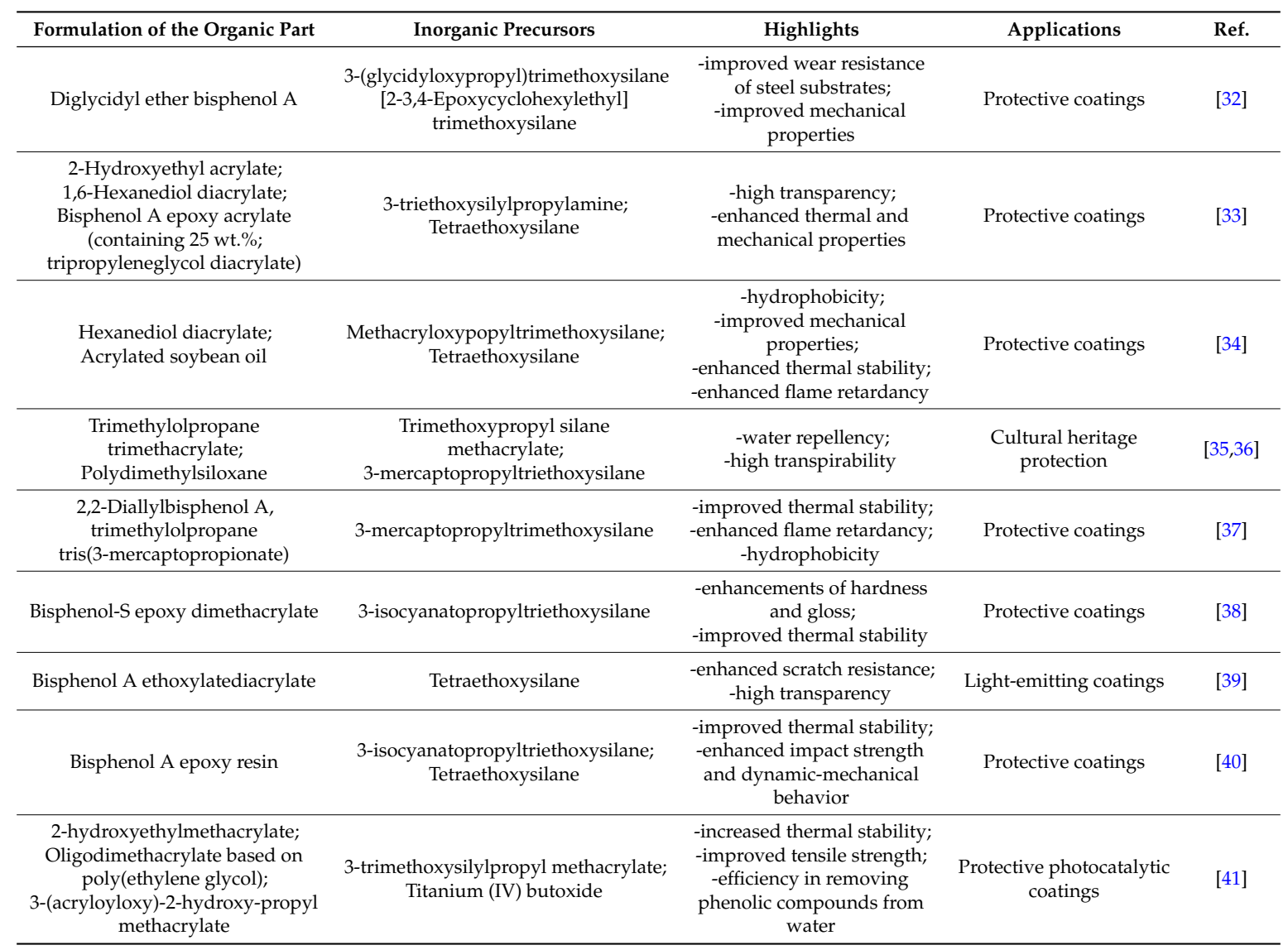

Recently, Cakmakci et al. prepared fluorine-containing hybrid coatings by combining UV-curing technology with an anhydrous sol-gel method [27] To this aim, methacryloxymethyltriethoxysilane was first hydrolyzed via an anhydrous sol-gel process; then, the obtained product was mixed with commercially available acrylic oligomers (namely, hexanediol diacrylate, a difunctional aliphatic polyester urethane acrylate oligomer diluted in tripropylene glycol diacrylate and a trifunctional polyester acrylate oligomer) and different amounts of fluoroacrylate resin. These UV-curable hybrid systems were coated on corona-treated polymethylmethacrylate substrates. SEM analyses showed the presence of silica particles homogenously dispersed throughout the organic matrix. Furthermore, the presence of fluorine provided flame retardancy and hydrophobic features to the obtained hybrid coatings, without affecting their optical properties (the optical transmittance was higher than 95\%). As a consequence, the proposed hybrids can be exploited as transparent protective coatings for flammable thermoplastic substrates.

Copuroglu and Sen exploited dual-cure processes for obtaining Zr-containing and organically-modified silicate-based hybrid systems bearing epoxy groups and, hence, suitable for cationic UV-curing [28]. The combination of the sol-gel reaction in the presence of suitable precursors (namely, 3-glycidyloxypropyltrimethoxysilane, Zirconium (IV) n-propoxide, tetraethoxysilane and dimethyldiethoxysilane) and the photopolymerization step allowed obtaining hybrids with enhanced mechanical properties and a high thermal stability, which make the hybrid potentially suitable for dental restoration/adhesion applications.

$\mathrm{Ni}$ and coworkers prepared a direct-to-metal protective hybrid coating that showed efficient barrier properties toward corrosion on aluminium alloy substrates [29]. More specifically, the hybrid coating was obtained from a mixture containing a diepoxy monomer (namely, diglycidyl ether of bisphenol A), n-alkyltrimethoxysilane precursors $\left(\mathrm{C}_{n} \mathrm{H}_{2 n+1} \mathrm{Si}\left(\mathrm{OCH}_{3}\right)_{3}\right.$ (with $\mathrm{n}$ ranging from 4 to 
16) and diaryl iodonium hexafluorophosphate salt, acting as a photoinitiator. This photoinitiator, upon UV exposure, was found to simultaneously catalyze the di-epoxy ring opening polymerization and the condensation of the organosilanes, giving rise to the formation of a highly crosslinked siloxane network. Salt spray tests and electrochemical impedance spectroscopy analyses demonstrated that the best anticorrosion performances were achieved when the metal substrate was coated with the poly(n-octylsilsesquioxane)/polyether coating. From an overall point of view, the n-alkyltrimethoxysilane precursors were responsible for the enhanced corrosion protection because of two reasons: i) they were able to increase the film hydrophobicity, and ii) they formed a silsesquioxane network that further improved the barrier effect already provided by the polyether network.

Very recently, Periolatto and Ferrero modified the surface of cotton and polyester fabrics in order to provide them with hydro and oil repellency. To this aim, sol-gel was coupled to post-UV-curing, aiming at improving the finishing adhesion to fibers, hence the treatment fastness [30]. In particular, 3-(trimethoxysilyl)propyl methacrylate was employed as sol-gel precursor both alone and with a perfluoropolyether bearing ethoxysilane terminal groups: thus, it was possible to prepare a UV-curable modified nanosol to be applied to fabrics with add-ons ranging from $5 \mathrm{wt} . \%$ to $30 \mathrm{wt} . \%$. The treated fabrics were subjected to contact angle measurements with water and oil; furthermore, resistance to washing was tested according to ISO standard [31] (for five washing cycles). It was found that the fluorinated additive was able to provide the treated fabrics with higher both hydro and oil repellency as compared with 3-(trimethoxysilyl)propyl methacrylate nanosol. Conversely, 3-(trimethoxysilyl)propyl methacrylate nanosol proved to be a good candidate as finishing agent to confer a significant hydrorepellency. Finally, UV post-curing improved the treatment fastness to washing.

Sangermano et al. exploited dual-cure processes for obtaining toughened hybrid coatings based on ethoxysilyl-modified hyperbranched aliphatic-aromatic polyesters embedded in epoxy-silica systems, where silica was generated through in situ sol-gel reactions starting from tetraethoxysilane [32]. For this purpose, photo-initiated cationic polymerization was successfully exploited and the chain transfer reaction of the phenolic terminal units of the modified hyperbranched polyesters was employed in order to effectively incorporate these toughening agents in the epoxy-silica system: indeed, the ethoxysilane groups were found to give rise to the formation of a strongly interconnected organic-inorganic network during the in-situ sol-gel process with tetraethoxysilane by binding the organic to the inorganic phase. This finding further confirms that the hyperbranched polyesters also act as multi-site coupling agents during the sol-gel reactions. The presence of $20 \mathrm{wt} . \%$ of tetraethoxysilane in the toughened epoxy system (i.e., containing $20 \mathrm{wt}$.\% of hyperbranched polyester) was responsible for an increase of the storage modulus and an improvement of the viscoelastic properties by increasing the $T_{\mathrm{g}}$ of the polymer matrix, hence extending the performance of the elastic modulus to higher temperatures. Apart from the improved thermo-mechanical behavior and increased surface hardness, the obtained hybrid coatings also showed a very high transparency.

Very recently, the same group succeeded in obtaining hybrid O/I coatings using 4-(hexahydropyrrolo[1,2- $\alpha$ pyrimidin-1-ylmethyl)-benzoic acid methyl ester as an efficient photocatalyst for triggering the concurrent base-catalyzed crosslinking of a formulation containing acrylate and acetoacetate functionalities in equimolar amounts via a Michael addition reaction, as well as the formation of silica domains through in situ sol-gel processes [33]. A general improvement of scratch resistance was observed for the hybrid coatings: this behavior was further enhanced when the size of the inorganic silica domains decreased.

Belon and co-workers exploited a dual UV-curing process that is able to trigger, in a single step, cationic photopolymerization and a photoinduced sol-gel process, for obtaining hybrid coatings on a steel substrate [34]. To this aim, an epoxy resin based on hydrogenated diglycidyl ether bisphenol A was mixed with two different organoepoxysilanes (namely, 3-(glycidyloxypropyl)trimethoxysilane and [2-(3,4-epoxycyclohexyl)ethyl]trimethoxysilane) in the presence of photoacid generator based on diaryliodonium salt. Different UV-cured coatings containing the organoepoxysilanes (from $20 \mathrm{wt} . \%$ to 
$50 \mathrm{wt} . \%)$ were prepared and a ball-on-disc tribometer was utilized for assessing their friction and wear properties. It was found that the presence of increased amounts of organoepoxysilanes improves the stiffness of the pure epoxy resin; conversely, an increase of the dynamic friction value was also found.

Quite recently, Xie and Shi succeeded in obtaining hybrid O/I coatings involving a photoinitiatorfree UV-curing and subsequent sol-gel processes [35]. The acrylate oligomers containing $\beta$-diketones were synthesized through the Michael addition and polyaddition reaction and their structures were confirmed by ${ }^{1} \mathrm{H}-\mathrm{NMR}$ and FT-IR analyses. The hybrid coatings showed outstanding uniformity and transparency in the presence of 15-60 wt.\% Si-sol loadings: this finding indicated that the silica domains were obtained in a small scale range in the polymer matrix. Thermogravimetric and dynamic-mechanical analyses showed improved thermal stability and mechanical properties of the hybrid coatings with respect to the pure polymer counterpart.

Basturk et al. utilized the dual-cure processes for preparing a series of methacrylated and phosphorylated epoxidized soybean oil/silica coatings, starting from tetraethoxysilane and acrylated soybean oil [36]. The designed UV-curable hybrid mixtures were coated on polycarbonate substrates, then exposed to UV radiation and post-cured at $100^{\circ} \mathrm{C}$ for $24 \mathrm{~h}$ in order to carry out the sol-gel process. Thermogravimetric analysis showed that the incorporation of the synthesized sol-gel precursor into the acrylic resin improved the thermal stability and, also, the flame retardancy properties (LOI up to 23\%) of the coated substrates. Furthermore, all the obtained hybrid coatings showed a hydrophobic character.

Esposito Corcione et al. exploited the dual-cure processes for preparing hybrid O/I coatings, suitable for the protection of a calcareous stone substrate (i.e., Pietra Leccese, from Apulia Region, Italy) [37,38]. To this aim, a "hybrid" UV-curable system consisting of $10 \mathrm{wt} . \%$ of trimethylolpropane trimethacrylate, $85 \mathrm{wt} . \%$ of trimethoxypropyl silane methacrylate and $5 \mathrm{wt} . \%$ of a polydimethylsiloxane functionalized with 3-mercaptopropyltriethoxysilane was prepared. Two different amounts of the "hybrid" liquid product were selected (namely, 0.88 and $1 \mathrm{~g} / 25 \mathrm{~cm}^{2}$ ) and applied on the stone substrate. Different performances were found according to the considered add-ons. More specifically, the lowest add-on was found to be suitable for treatments requiring a very slight color variation to naked eye; conversely, the highest quantity of hybrid formulation provided an outstanding water repellency (contact angle values around $130^{\circ}$ ), and a high transpirability of the stone substrate, as well.

Sen and Kahraman prepared dual-curable cyanate ester/boron phosphate hybrids, using 3-mercaptopropyltrimethoxysilane as precursor of the inorganic phase and exploiting a thiol-ene photopolymerization followed by a thermal treatment [39]. The obtained products are suitable for high performance applications in such fields as aerospace industry and electronics and may represent an interesting alternative to the standard materials employed there. Indeed, the obtained composites showed an improved thermal stability: in particular, the char yield was found to increase with increasing the trimethoxysilane and boron phosphate contents. The glass transition temperatures of the hybrids were found to increase in the presence of trimethoxysilane and boron phosphate, from $202{ }^{\circ} \mathrm{C}$ (neat polymer matrix) up to $223^{\circ} \mathrm{C}$ (hybrid containing the highest amounts of trimethoxysilane and boron phosphate), due to the lowering of the polymer chain mobility. Similarly, the presence of the silica together with boron phosphate increased the thermal stability and flammability properties (LOI values ranged from $28 \%$ to $33 \%$ ) of the polymer matrix. Finally, unlike boron phosphate, the presence of the silica phase, $\mathrm{s}$ as a consequence of the sol-gel reactions, turned out to improve the hydrophobic character of the hybrids (contact angle values with water raised from $83^{\circ}$ to $104^{\circ}$ ).

$\mathrm{Li}$ et al. synthesized a hybrid oligomer through the modification of a bisphenol-S epoxy dimethacrylate with different amounts of 3-isocyanatopropyltriethoxysilane, used both as coupling agent and silica source [40]. The modification degree of the hybrid oligomer was varied from 0 to $70 \mathrm{wt} . \%$. After exposure to UV-radiation, the glass plates coated with the hybrid formulations were immersed in water at $100{ }^{\circ} \mathrm{C}$ in acidic conditions to facilitate the hydrolysis of the ethoxysilane groups, and then thermally treated in order to carry out the condensation reactions. Despite poor adhesion on the glass substrates, the hybrid coatings showed significant hardness and gloss enhancements; 
furthermore, the $T_{\mathrm{g}}$ values were found to increase (from 134 to $161^{\circ} \mathrm{C}$ ) due to the presence of the in situ-generated silica phase, which also improved the thermal stability of the polymer matrix.

Roppolo et al. succeeded in obtaining dual-cured transparent light-emitting hybrid $\mathrm{O} / \mathrm{I}$ coatings, starting from mixtures of Bisphenol A ethoxylatediacrylate with silica precursors (namely, tetraethoxysilane and methacryloyloxypropyltrimethoxysilane) and photoluminescent copper iodide $\left[\mathrm{Cu}_{4} \mathrm{I}_{4} \mathrm{~L}_{4}\right.$, where $\mathrm{L}=\mathrm{PPh}_{2}\left(\mathrm{CH}_{2}\right)_{2} \mathrm{CH}_{3}$ ] clusters [41]. In addition to an enhanced scratch resistance, the hybrid coatings showed a high transparency up to a content of $30 \mathrm{wt} . \%$ of tetraethoxysilane in the liquid "hybrid" formulation, as well as a bright luminescence with a maximum of emission centered at $565 \mathrm{~nm}$ (yellow-orange).

Quite recently, Bi and co-workers exploited the dual-cure processes for obtaining epoxy/silica hybrid coatings, suitable for such applications as protective coatings, adhesives, inks, and so on [42]. For this purpose, an epoxy oligomer bearing ethoxy functionalities was obtained by reacting 3-isocyanatopropyltriethoxysilane with a standard Bisphenol A epoxy resin; then, a "hybrid" mixture containing the epoxy resin, the modified epoxy oligomer and tetraethoxysilane (silica precursor) was subjected to cationic photopolymerization followed by a thermal treatment for the occurrence of the sol-gel reactions. Transmission electron microscopy analyses showed that the in situ-generated silica nanoparticles (average size: around $40 \mathrm{~nm}$ ) were homogeneously dispersed in the epoxy matrix and were able to significantly increase the thermal stability, the impact strength, and the dynamic-mechanical behavior of the obtained hybrid coatings.

Chibac and co-workers recently assessed the possibility of using dual-cured hybrid organic/inorganic coatings for photocatalytic applications [43]. To this aim, an acid urethane oligodimethacrylate based on poly(ethylene glycol) was synthesized and exploited for preparing hybrid coatings containing silsesquioxane sequences and titania domains in situ formed through sol-gel reactions; the UV-curing step was also utilized for in situ generation of silver/gold nanoparticles. The hybrid coatings, in addition to an increased thermal stability and an improved tensile strength, were found to be suitable for the complete removal of organic pollutants (i.e., phenolic compounds) from water under UV irradiation (200-350 $\mathrm{min}$ ) at low intensity (similar to that provided by sunlight).

\section{Conclusions}

This review has clearly demonstrated the importance of hybrid organic-inorganic coatings as innovative, advanced, smart, functional, protective materials, suitable for different application fields, including optics, electronics, mechanics, environment, etc. Surely, among all of the different strategies that can be successfully exploited for obtaining hybrid coatings, dual-cure processes, involving a photo-induced polymerization followed by a thermal treatment (for the occurrence of sol-gel reactions), seem to represent an easy, feasible, and affordable way for designing well-controlled hybrid organic-inorganic architectures. Therefore, it can be foreseen that the use of these dual-cure processes for preparing hybrid materials in form of coatings could be widened and also up-scaled, hence becoming closer to industrial applications. It may be possible that the fundamental and technological developments associated with the wide hybrid coatings domain are currently limited only by the imagination of the different researchers dealing with materials, and possessing complementary skills and competences, like chemists, materials scientists, physicists, and engineers.

Conflicts of Interest: The author declares no conflict of interest.

\section{References}

1. Drisko, G.L.; Sanchez, C. Hybridization in materials science-Evolution, current state, and future aspirations. Eur. J. Inorg. Chem. 2012, 2012, 5097-5105. [CrossRef]

2. Sanchez, C.; Ribot, F. Design of hybrid organic-inorganic materials synthesized via sol-gel chemistry. New J. Chem. 1994, 18, 1007-1047. 
3. Yano, S.; Iwata, K.; Kurita, K. Physical properties and structure of organic-inorganic hybrid materials produced by sol-gel process. Mater. Sci. Eng. C 1998, 6, 75-90. [CrossRef]

4. Wen, J.; Wilkes, G.L. Organic/inorganic hybrid network materials by the sol-gel approach. Chem. Mater. 1996, 8, 1667-1681. [CrossRef]

5. Judeinstein, P.; Sanchez, C. Hybrid organic-inorganic materials: A land of multidisciplinarity. J. Mater. Chem. 1996, 6, 511-525. [CrossRef]

6. Gomez-Ribero, P.; Sanchez, C. Functional Hybrid Materials; Wiley-VCH: Wienheim, Germany, 2004.

7. Mascia, L. Developments in Organic-Inorganic Polymeric Hybrids: Ceramers. Trends Polym. Sci. 1995, 3, 61-66.

8. Sanchez, C.; Julian, B.; Belleville, P.; Popall, M. Applications of hybrid organic-inorganic nanocomposites. J. Mater. Chem. 2005, 15, 3559-3592. [CrossRef]

9. Nicole, L.; Laberty-Robert, C.; Rozes, L.; Sanchez, C. Hybrid materials science: A promised land for the integrative design of multifunctional materials. Nanoscale 2014, 6, 6267-6292. [CrossRef] [PubMed]

10. Kickelbick, G. Hybrid Materials; Wiley-VCH: Wienheim, Germany, 2003.

11. Letailleur, A.A.; Ribot, F.; Boissière, C.; Teisseire, J.; Barthel, E.; Desmazieres, B.; Chemin, N.; Sanchez, C. Sol-gel derived hybrid thin films: The chemistry behind processing. Chem. Mater. 2011, 23, 5082-5089. [CrossRef]

12. Hajji, P.; David, L.; Gerard, J.F.; Pascault, J.P.; Vigier, G. Synthesis, structure, and morphology of polymer-silica hybrid nanocomposites based on hydroxyethyl methacrylate. J. Polym. Sci. Part B Polym. Phys. 1999, 37, 3172-3179. [CrossRef]

13. Wei, Y.; Jin, D.; Xu, J.; Baran, G.; Qiu, K.Y. Mechanical properties of interface-free polyacrylate-silica hybrid sol-gel materials for potential dental applications. Polym. Adv. Technol. 2001, 12, 361-368. [CrossRef]

14. Wu, K.H.; Chang, T.C.; Wang, Y.T.; Chiu, Y.S. Organic-inorganic hybrid materials. I. Characterization and degradation of poly(imide-silica) hybrids. J. Polym. Sci. Polym. Chem. 1999, 37, 2275-2284. [CrossRef]

15. Zhu, Z.; Yang, Y.; Yin, J.; Qi, Z. Preparation and properties of organosoluble polyimide/silica hybrid materials by sol-gel process. J. Appl. Polym. Sci. 1999, 73, 2977-2984.

16. Innocenzi, P.; Brusatin, G.; Babonneau, F. Competitive polymerization between organic and inorganic networks in hybrid materials. Chem. Mater. 2000, 12, 3726-3732. [CrossRef]

17. Malucelli, G. Preparation and characterization of nanocomposite coatings obtained through UV-curing processes. In Nanocomposites: Synthesis, Characterization and Applications; Wang, X., Ed.; NOVA Science Publishers, Inc.: New York, NY, USA, 2011; pp. 139-167.

18. Cho, J.; Ju, H.; Hong, J. Photocuring kinetics of UV-initiated free-radical photopolymerizations with and without silica nanoparticles. J. Polym. Sci. Part A Polym. Chem. 2005, 43, 658-670. [CrossRef]

19. Malucelli, G.; Priola, A.; Sangermano, M.; Amerio, E.; Zini, E.; Fabbri, E. Hybrid nanocomposites containing silica and PEO segments: Preparation through dual-curing process and characterization. Polymer 2005, 46, 2872-2879. [CrossRef]

20. Amerio, E.; Sangermano, M.; Malucelli, G.; Priola, A.; Voit, B. Preparation and characterization of hybrid nanocomposite coatings by photopolymerization and sol-gel process. Polymer 2005, 46, 11241-11246. [CrossRef]

21. Innocenzi, P.; Brusatin, G. A comparative FTIR study of thermal and photo-polymerization processes in hybrid sol-gel films. J. Non-Cryst. Solids 2004, 333, 137-142. [CrossRef]

22. Chou, T.P.; Chandrasekaran, C.; Cao, G.Z. Sol-gel-derived hybrid coatings for corrosion protection. J. Sol-Gel Sci. Technol. 2003, 26, 321-327. [CrossRef]

23. Van Bommel, M.J.; ten Wolde, P.M.C.; Bernards, T.N.M. The influence of methacryloxypropyltrimethoxysilane on the sol-gel process of TEOS. J. Sol-Gel Sci. Technol. 1994, 2, 167-170. [CrossRef]

24. Flores, M.; Foix, D.; Serra, A.; Ramis, X.; Sangermano, M. A versatile thiol-ene/sol-gel two-stage curing process based on a hyperbranched polyester with different degrees of 10-undecenoyl modification. Macromol. Mater. Eng. 2014, 299, 495-503. [CrossRef]

25. Chiang, C.; Ma, C.M.; Wu, D.L.; Kuan, H.C. Preparation, characterization, and properties of novolac-type phenolic $/ \mathrm{SiO}_{2}$ hybrid organic-inorganic nanocomposite materials by sol-gel method. J. Polym. Sci. Part A Polym. Chem. 2003, 41, 905-913. [CrossRef]

26. Mammeri, F.; Le Bourhis, E.; Rozesa, L.; Sanchez, C. Mechanical properties of hybrid organic-inorganic materials. J. Mater. Chem. 2005, 15, 3787-3811. [CrossRef] 
27. Cakmakci, E.; Altıntas, Z.; Kahraman, M.V.; Apohan, N.K. Fluorine-containing photocurable hybrid coatings via anhydrous sol-gel method. J. Vinyl Additive Technol. 2015, 21, 272-277. [CrossRef]

28. Copuroglu, M.; Sen, M. Synthesis and characterization of a Zr-containing silicate-based epoxy-functional polymer nanocomposite system. Polym. Eng. Sci. 2015, 55, 792-798. [CrossRef]

29. Ni, L.; Chemtob, A.; Croutxé-Barghorn, C.; Moreau, N.; Bouder, T.; Chanfreau, S.; Pébère, N. Direct-to-metal UV-cured hybrid coating for the corrosion protection of aircraft aluminium alloy. Corros. Sci. 2014, 89, 242-249. [CrossRef]

30. Periolatto, M.; Ferrero, F. Cotton and polyester surface modification by methacrylic silane and fluorinated alkoxysilane via sol-gel and UV-curing coupled process. Surf. Coat. Technol. 2015, 271, 165-173. [CrossRef]

31. ISO 105-C01:1989 Textiles-Tests for Colour Fastness_Part C01: Colour Fastness to Washing: Test 1; ISO: Geneva, Switzerland, 1989.

32. Sangermano, M.; El Sayed, H.; Voit, B. Ethoxysilyl-modified hyperbranched polyesters as multifunctional coupling agents for epoxy-silica hybrid coatings. Polymer 2011, 52, 2103-2109. [CrossRef]

33. Gigot, A.; Sangermano, M.; Capozzi, L.C.; Dietliker, K. In-situ synthesis of organic-inorganic coatings via a photolatent base catalyzed Michael-addition reaction. Polymer 2015, 68, 195-201. [CrossRef]

34. Belon, C.; Schmitt, M.; Bistac, S.; Croutxé-Barghorn, C.; Chemtob, A. Friction and wear properties of hybrid sol-gel nanocomposite coatings against steel: Influence of their intrinsic properties. Appl. Surf. Sci. 2011, 257, 6618-6625. [CrossRef]

35. Xie, H.; Shi, W. Polymer/ $\mathrm{SiO}_{2}$ hybrid nanocomposites prepared through the photoinitiator-free UV curing and sol-gel processes. Compos. Sci. Technol. 2014, 93, 90-96. [CrossRef]

36. Basturk, E.; Inan, T.; Güngor, A. Flame retardant UV-curable acrylated epoxidized soybean oil based organic-inorganic hybrid coating. Prog. Org. Coat. 2013, 76, 985-992. [CrossRef]

37. Esposito Corcione, C.; Striani, R.; Frigione, M. Novel hydrophobic free-solvent UV-cured hybrid organic-inorganic methacrylic-based coatings for porous stones. Prog. Org. Coat. 2014, 77, 803-812. [CrossRef]

38. Esposito Corcione, C.; Striani, R.; Frigione, M. Organic-inorganic UV-cured methacrylic-based hybrids as protectivecoatings for different substrates. Prog. Org. Coat. 2014, 77, 1117-1125. [CrossRef]

39. Sen, F.; Kahraman, M.V. Hybrid dual-curable cyanate ester/boron phosphate composites via sequential thiol-ene photopolymerization and thermal polymerization. Prog. Org. Coat. 2014, 77, 1053-1062. [CrossRef]

40. Li, C.; Cheng, J.; Yang, F.; Chang, W.; Nie, J. Preparation and Characterization of UV-Cured Hybrid Coatings by Triethoxysilane-Modified Dimethacrylate Based on Bisphenol-S Epoxy. J. Appl. Polym. Sci. 2013, 129, 2189-2195. [CrossRef]

41. Roppolo, I.; Messori, M.; Perruchas, S.; Gacoin, T.; Boilot, J.P.; Sangermano, M. Multifunctional luminescent organic/inorganic hybrid films. Macromol. Mater. Eng. 2012, 297, 680-688. [CrossRef]

42. Bi, Y.T.; Li, Z.J.; Liang, W. Preparation and characterization of epoxy $/ \mathrm{SiO}_{2}$ nanocomposites by cationic photopolymerization and sol-gel process. Polym. Adv. Technol. 2014, 25, 173-178. [CrossRef]

43. Chibac, A.L.; Melinte, V.; Buruiana, T.; Mangalagiu, I.; Buruiana, E.C. Preparation of photocrosslinked sol-gel composites based on urethane- acrylic matrix, silsesquioxane sequences, $\mathrm{TiO}_{2}$, and $\mathrm{Ag} / \mathrm{Au}$ nanoparticles for use in photocatalytic applications. J. Polym. Sci. Part A Polym. Chem. 2015, 53, 1189-1204. [CrossRef]

(C) 2016 by the author; licensee MDPI, Basel, Switzerland. This article is an open access article distributed under the terms and conditions of the Creative Commons by Attribution (CC-BY) license (http://creativecommons.org/licenses/by/4.0/). 